\title{
Seasonal expressions of VEGF and its receptors VEGFR1 and VEGFR2 in the prostate of the wild ground squirrels (Spermophilus dauricus)
}

\author{
Yuchen Yao, Wenqian Xie, Di Chen, Yingying Han, Zhengrong Yuan, Haolin Zhang, Qiang Weng \\ Laboratory of Animal Physiology, College of Biological Sciences and Technology, Beijing Forestry University, Beijing, \\ China
}

As a vital male accessory reproductive gonad, the prostate requires vascular endothelial growth factors for promoting its growth and development. In this study, we investigated the localizations and expressions of vascular endothelial growth factor (VEGF) and its receptors including VEGF-receptor1 (VEFGR1) and VEGF-receptor2 (VEGFR2) in the prostate of the wild ground squirrels during the breeding and the non-breeding seasons. The values of total prostate weight and volume in the breeding season were higher than those in the non-breeding season. Histological observations showed that the exocrine lumens of the prostate expanded in the breeding season and contracted in the non-breeding season. The mRNA expression levels of VEGF and VEGFR2 in the prostate were higher in the breeding season than those in the non-breeding season, but the mRNA expression level of VEGFR1 had no significant change between the breeding and non-breeding seasons. Immunohistochemical results revealed that VEGF, VEGFR1 and VEGFR2 were presented in epithelial and stromal cells during the breeding and non-breeding seasons. In addition, the microvessels of the prostate were widely distributed and the number of microvessels increased obviously in the breeding season, while decreased sharply in the non-breeding season. These results suggested that expression levels of VEGF and VEGFR2 might be correlated with seasonal changes in morphology and functions of the prostate, and VEGF might serve as pivotal regulators to affect seasonal changes in the prostate functions of the wild male ground squirrels via an autocrine/paracrine pathway.

Key words: Prostate; VEGF; VEGFR1; VEGFR2; wild ground squirrel.

Correspondence: Qiang Weng, Ph.D., Laboratory of Animal Physiology, College of Biological Sciences and Biotechnology, Beijing Forestry University, Beijing 100083, China. Tel. +86.10.6233-8682.

E-mail: qiangweng@bjfu.edu.cn

Contributions: YY, WX, DC, YH, participated in performing the experiments, analyzing the data and drafting the manuscript; YY, WX, HZ, ZY, assisted with sample collection, all experiments and helped revising the manuscript; YH, HZ, QW, designed, supervised the study, and revised manuscript. All authors read and approved the final version of this manuscript and agreed to be accountable for all aspects of the work.

Conflict of interest: The authors declare that they have no competing interests, and all authors confirm accuracy.

Ethical Approval: All the procedures on animals were carried out in accordance with the policy on the Care and Use of Animals by the Ethical Committee, Beijing Forestry University and approved by the Department of Agriculture of Hebei province, China (JNZF11/2007). 


\section{Introduction}

As a part of the male reproductive tract in mammals, the prostate has always played a unique and irreplaceable role. Although the prostate is present in many mammalian species, the growth, development, morphology and function of the prostate vary widely among mammals. ${ }^{1}$ It is a compact solitary structure in humans, while in rodents, such as the mouse, the prostate is made up of distinct lobes. ${ }^{2,3}$ The prostate is comprised of epithelial and stromal elements, and tall columnar secretory epithelial cells are lined in the duct that are surrounded by stromal cells. ${ }^{4,5}$ The stromal cells is consisted of smooth muscle cells, fibroblasts, myofibroblasts, vascular endothelial cells, nerve cells, and inflammatory cells. ${ }^{5}$ The prostate has a variety of physiological functions, and its main function is to produce a slightly alkaline liquid, which is one of the main components of seminal plasma. This can provide sperm with nutrition and protection to stimulate sperm capacitation and to promote the formation of fertilized eggs. ${ }^{6}$ The development and function of the prostate are not invariable. In seasonal breeding animals, ${ }^{7,8}$ there were obvious seasonal changes in the shape and function of the prostate. In humans, the prostate expands with the increase of age and leads to a range of diseases, including benign prostatic hyperplasia and the prostate cancer. ${ }^{9}$ This process involves the regulation of various endocrine and local factors, the most obvious of which are sex steroids and downstream growth factors. ${ }^{10,11}$

Vascular endothelial growth factor (VEGF) is a protein with angiogenic activity and a potent stimulator of microvascular permeability. ${ }^{11,12}$ It plays an important role in physiological and pathological neovascularization via its receptors Flt1/VEGFR1 and kinase insert domain containing region (KDR)/VEGFR2, both of which have tyrosine kinase activity. ${ }^{13}$ During the processes of neovascularization, endothelial glycoprotein CD105, as a specific marker of microvascular density, participates in the proliferation and migration of endothelial cells in response to VEGF signaling. ${ }^{14}$ Existing literature suggested that in mammals the regulation of sex steroid hormone for VEGF plays an important role, a lot of studies found that the level of LH was closely related to that of VEGF and induced the expression of VEGF. ${ }^{15,16}$ In the mammalian reproductive system, the regulation effect of sex steroid hormone on VEGF is more obvious. In female mammals, FSH and $\mathrm{LH}$ regulated VEGF expression in the uterus and ovaries. ${ }^{17,18}$ In male animals, VEGF played an important role in testicular development under the regulation of sex steroid hormone..$^{19,20}$ In recent years, it has been found that VEGF plays an important role in the development of mammalian prostate and human prostate tumor. ${ }^{21,22}$

The wild ground squirrel (Spermophilus dauricus) is a typical seasonal breeder that has a shorter breeding season from April to May, following with a longer non-breeding season from June to March of next year. ${ }^{23,24}$ The seasonal switch of reproductive system between the breeding and non-breeding seasons provides us a unique model to study the functional regulation of the male reproductive tract. ${ }^{25}$ Our previous studies have found that seasonal change of cyclooxygenases-1 (COX-1), cyclooxygenases-2 (COX2 ), prostaglandins E2 (PGE2) receptor and androgen receptor (AR) were correlated with circulating concentrations of testosterone (T) and dihydrotestosterone (DHT) in the prostate of the wild ground squirrels. ${ }^{26,27}$ To extend our knowledge, in this study, we investigated the expression patterns of VEGF, VEFGR1 and VEFGR2 in the prostate of the wild ground squirrels during the breeding and nonbreeding seasons, to gain a better understanding of the relationship between VEGF system and the seasonal changes of the prostate functions in the wild ground squirrels.

\section{Materials and Methods}

\section{Animals and tissues collection}

The wild ground squirrels were collected from the grassland of Zhangjiakou, Hebei Province, China on April 19 ${ }^{\text {th }}, 2018$ (the breeding season, $\mathrm{n}=11$ ) and on September 24th 2018 (the nonbreeding season, $n=12$ ). The wild ground squirrels were weighed and sacrificed after deep anaesthesia with ether. After the prostate samples were quickly removed and dissected, their weights were immediately measured using a balance. Then the length, width and thickness of prostate were also measured and the prostate volume was calculated by multiplying these three values. Parts of the prostate samples were placed in freezing tubes and immediately frozen in liquid nitrogen for mRNA detection. The other parts of the prostates were preserved in $4 \%$ paraformaldehyde (SigmaAldrich, St. Louis, MO, USA) for future histological and immunohistochemical observations.

\section{Histology}

The fixed prostate or testicular samples were dehydrated in ethanol-xylene series and embedded in paraffin wax. Successive sections $(5 \mu \mathrm{m})$ were attached to poly-L-lysine (Sigma-Aldrich) coated slides. The sections were histologically observed with hematoxylin and eosin. The remaining sections were treated and observed by immunohistochemistry.

\section{Immunohistochemistry}

Simply stated, paraffin sections of the prostates were deparaffined with xylene-ethanol series, followed by antigen retrieval using autoclave at $121^{\circ} \mathrm{C}$ for $10 \mathrm{~min}$. In order to reduce the nonspecific background staining caused by endogenous peroxidase, sections were incubated in the $0.3 \%$ hydrogen peroxide diluted with methanol for $30 \mathrm{~min}$. And then the sections were hatched with $10 \%$ normal goat serum (C-0005, Beijing Biosynthesis Biotechnology Co. Ltd., Beijing, China) to diminish background discoloration and then incubated with primary rabbit polyclonal antibodies (1:500 dilutions) against CD105 (bs-0579R) (Bioss Antibodies, Beijing, China), VEGF (bs-0279R) (Bioss Antibodies), VEGFR1 (bs-0170R) (Bioss Antibodies), VEGFR2 (bs-1142R) (Bioss Antibodies), PSA (bs-1964R) (Bioss Antibodies) for $12 \mathrm{~h}$ at $4^{\circ} \mathrm{C}$. After that, incubations with the secondary antibody, goat anti-rabbit IgG (c-0006; Bioss Antibodies) bound to biotin, and peroxidase bound to avidin, using SP toolkit (Rabbit) (SP-0023; Beijing Biosynthesis Biotechnology) was performed, followed by incubation with $30 \mathrm{mg} \mathrm{3,3'-diaminobenzidine}$ (DAB) (Wako, Tokyo, Japan) solution in $150 \mathrm{~mL}$ of $0.05 \mathrm{M}$ Tris$\mathrm{HCl}$ buffer, $\mathrm{pH} 7.6$, plus $30 \mu \mathrm{H}_{2} \mathrm{O}_{2}$. The specificity of VEGF, VEGFR1 and VEGFR2 antibodies has been described in our previous studies. ${ }^{28}$ Normal goat serum was selected to replace the initial antiserum treatment in the sections of the control group. The DAB staining was evaluated using ImageJ and the integrated density of positive staining area were calculated. Based on the rank of integrated density, immunohistochemical staining results were marked as positive $(+)$, strong positive $(++)$, very strongly positive $(+++)$ and negative $(-)$.

\section{RNA isolation}

Thawed $100 \mathrm{mg}$ or so of the prostate samples and immediately mixed in $1000 \mu \mathrm{L}$ of Trizol reagent (Invitrogen Co., CA, USA) and homogenized with an ultrasonic crusher. The resulting homogenate was incubated on ice for $10 \mathrm{~min}$ to complete the dissociation of the nucleoprotein complexes. After $200 \mu \mathrm{L}$ chloroform was added to the mixture, the mixture was shaken forcefully for $15 \mathrm{~s}$, and centrifuged at $12,000 \times \mathrm{g}$ and $4^{\circ} \mathrm{C}$ for $20 \mathrm{~min}$. The aqueous phase was transferred to 
the RNase free tube and mixed with isopropyl alcohol of equal volume. Then the tubes were kept on ice for $10 \mathrm{~min}$. RNA was precipitated by centrifugation at $12,000 \times \mathrm{g}$ and $4^{\circ} \mathrm{C}$ for $20 \mathrm{~min}$. The newly obtained RNA particles were washed twice with $70 \%$ ethanol, dried briefly in a super-clean workbench, and then shaken and mixed in $50 \mu \mathrm{L}$ of diethylpropane-treated water. Finally, the integrity of RNA was detected by gel electrophoresis and the concentration of RNA was determined by spectrophotometer.

\section{qRT-PCR}

The cDNA in the sample was synthesized using a reverse transcription kit (GenStar, Beijing, China). The target genes of the prostate sample were treated with a designed primer (Table 1) for quantitative realtime PCR detection. The exact reaction circumstances were followed: pre-denaturation at $95^{\circ} \mathrm{C}$ for $10 \mathrm{~min}$, followed by a total of 40 cycles at $95^{\circ} \mathrm{C}$ for $30 \mathrm{~s}, 60^{\circ} \mathrm{C}$ for $30 \mathrm{~s}$, and $72^{\circ} \mathrm{C}$ for $30 \mathrm{~s}$. After that, dissolution curvature was distinguished. The expression level of each target mRNA relative to $\beta$-actin mRNA was regulated using the $2^{-\Delta \Delta C t}$ method.

\section{Microvascular counts in the prostate}

Clusters of cells with the positive staining for CD105 were counted as blood vessels. Three random areas under $400 \times$ microscopic fields of vision in each section were chosen for microvessels counting. The microvascular density was calculated with the number of stained microvessels divided by area $\left(\mathrm{mm}^{2}\right)$. Vessels with diameters greater than the lengths of 8 red blood cells or with thick-walls were not included in the counting range. At least 5 sections in each period were observed in each sample. Finally, two researchers with rich experimental experience counted them separately and calculated the mean value.

\section{Statistical analysis}

All results were presented as mean \pm standard deviation (SD), and the normality and homoscedasticity tests were evaluated by Shapiro-
Wilk test and F test, respectively. And statistical significance between differences groups was ensured by two-tailed unpaired Student's $t$-test. The linear correlations were performed by linear regression and the goodness of fit was presented by calculating the Pearson correlation coefficients (R square value). The statistical analysis was carried out by Prism 6.0 (GraphPad Software, San Diego, CA, USA) and a value of $\mathrm{p}<0.05$ was considered indication of statistical significance.

\section{Results}

\section{Morphological and histological features of the prostate}

The prostatic morphology of the wild ground squirrels was observed in both the breeding and non-breeding seasons (Figure 1). The prostate was located at the junction between the bladder and the urethra (Figure 1a). The prostate showed obviously morphological changes between the breeding season (Figure 1b) and the non-breeding season (Figure 1c). The average value of the

\section{Table 1. Oligonucleotide primers used for qPCR.}

\begin{tabular}{|c|c|c|}
\hline & Sequence of primer & Product size (bp) \\
\hline$V E G F$ & $\begin{array}{l}\text { F: 5'GAGCCTTGCCTTGCTGCTCTAC3' } \\
\text { R: 5'CACCAGGGTCTCGATTGGATG3' }\end{array}$ & 174 \\
\hline VEGFRI & $\begin{array}{l}\text { F: 5'AGAACCCCGATTATGTGAGAAA3' } \\
\text { R: 5'GATAGATTCGGGAGCCATCC3' }\end{array}$ & 232 \\
\hline VEGFR2 & $\begin{array}{l}\text { F: 5'GAACATTTGGGAAATCTCTTGC3' } \\
\text { R: 5'CGGAAGAACAATGTAGTCTTTGC3' }\end{array}$ & 187 \\
\hline$\beta$-actin & $\begin{array}{l}\text { F: 5'GACTCGTCGTACTCCTGCTT3' } \\
\text { R: 5'AAGACCTCTATGCCAACACC3' }\end{array}$ & 233 \\
\hline
\end{tabular}
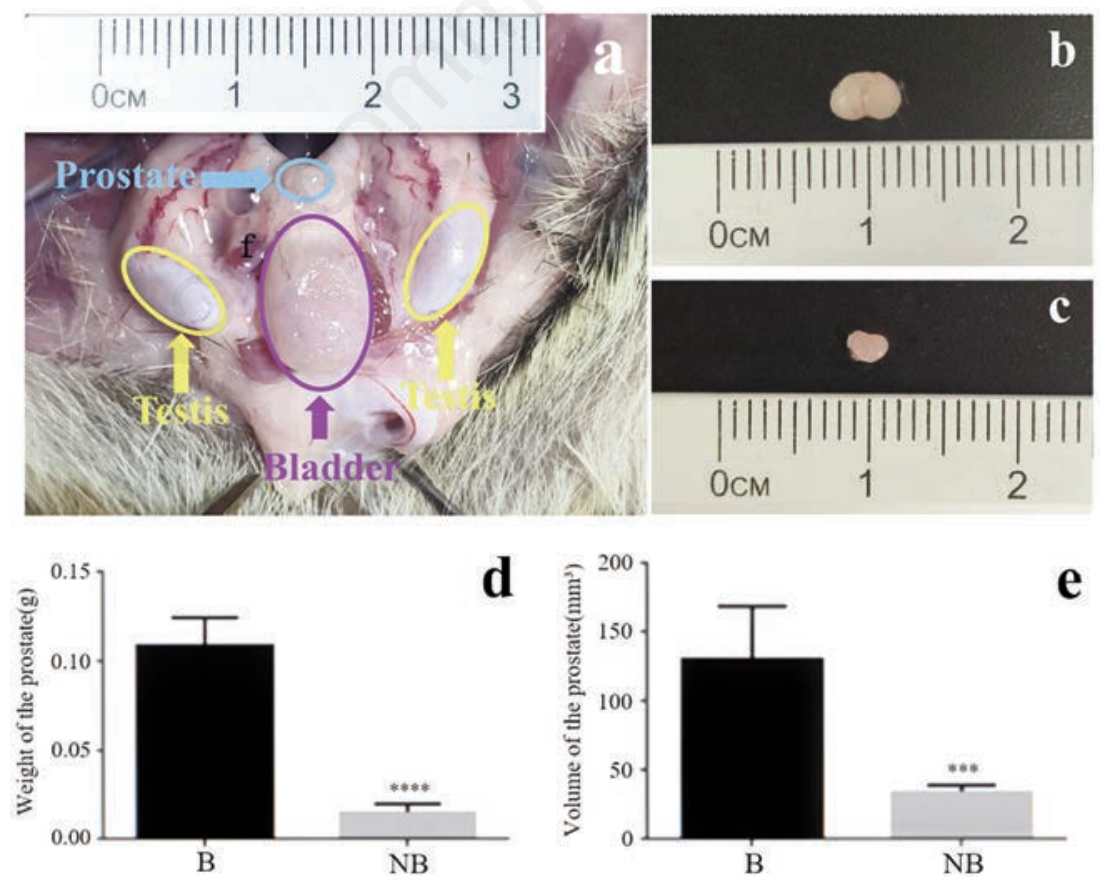

Figure 1. Morphological features of the prostate of the wild ground squirrels in the breeding season and the non-breeding season. a) Anatomic localization and morphology of the prostate gland in the wild ground squirrel; the blue arrow indicates the location of the prostate. Morphological observation of the fresh the prostate in the breeding season (b) and the non-breeding season (c). The average weight (d) and volume (e) of the prostate in the breeding and non-breeding seasons. B, the breeding season; NB, the non-breeding season. The error bars represent the $\mathrm{SD}\left(\mathrm{n}=5\right.$, each period). ${ }^{* * *} \mathrm{p}<0.001 ;{ }^{* * * *} \mathrm{p}<0.0001$. 
prostate weight and volume of the wild ground squirrels were significantly higher during the breeding season than those during the non-breeding season (Figure $1 \mathrm{~d}, \mathrm{e}$ ).

Prostate specific antigen (PSA) was used to label the prostate of the wild ground squirrels during the breeding and non-breeding seasons (Figure $2 \mathrm{a}, \mathrm{b}$ ). The prostate of the wild ground squirrels was composed mainly of two main types of cells including epithelial cells and stromal cells (Figure $2 \mathrm{c}, \mathrm{d}$ ). The testicular morphology was observed to confirm the reproductive status of the wild ground squirrel. The results showed that the mature spermatids in the seminiferous tubules were found in the breeding season, whereas no mature spermatids were observed in the non-breeding season (Figure $2 \mathrm{e}, \mathrm{f}$ ).

\section{Immunohistochemical localizations of VEGF, VEGFR1} and VEGFR2 in the prostate of the wild ground squirrels

The immunohistochemical localizations of VEGF, VEGFR1 and VEGFR2 in the prostate of the wild ground squirrels were shown in Figure 3. Additionally, VEGF, VEGFR1 and VEGFR2 showed immunoreactivity responses in epithelial and stromal cells during the breeding and non-breeding seasons (Figure 3 a-f), while the immunoreactivity responses of VEGF, VEGFR1 and VEGFR2 in the epithelial cells were stronger than those in the stromal cells. No signal was detected in the negative controls (Figure $3 \mathrm{~g}$,h). All staining images of VEGF, VEGFR1 and VEGFR2 were quantified and summarized in Table 2 .

\section{The mRNA expressions of VEGF, VEGFR1 and} VEGFR2 in the prostate of the wild ground squirrels

The mRNA levels of VEGF, VEGFR1 and VEGFR2 (tran- scripts from the genes $V E G F, V E G F R 1$ and $V E G F R 2$, respectively) were assessed by qPCR (Figure $4 \mathrm{a}-\mathrm{c}$ ). The mRNA expression levels of $V E G F$ and $V E G F R 2$ were significantly higher in the breeding season than those of the non-breeding season (Figure 4 a,c), while the mRNA expression level of VEGFR1 showed no difference between the two different seasons (Figure $4 \mathrm{~b}$ ).

The linear correlation and scatter diagram of relative mRNA expressions levels of VEGF, VEGFR1, VEGFR2 and weights of the prostate of the wild ground squirrels during the breeding and non-breeding seasons were shown in Figure 5. Scatter diagram of relative expressions of $V E G F$ and $V E G F R 2$ were positively correlated with the weights of the prostate $(\mathrm{p}<0.01)$ (Figure $5 \mathrm{a}, \mathrm{c})$, while the relative expression levels of VEGFR1 were not correlated with the weights of the prostate of the wild ground squirrels (Figure 5b).

Table 2. Relative abundance of target proteins in the prostate of the wild ground squirrels during the breeding and non-breeding seasons.

\begin{tabular}{lccccc} 
& & SC & & EC \\
& B & NB & B & NB \\
VEGF & ++ & ++ & +++ & +++ \\
VEGFR1 & + & ++ & +++ & +++ \\
\hline VEGFR2 & + & ++ & +++ & +++ \\
\hline
\end{tabular}

Immunohistochemical staining results were marked as positive $(+)$, strong positive $(++)$, very strongly positive $(+++)$ and negative $(-)$ by ImageJ. SC, stromal cell; EC, epithelial cell; B, the breeding season; NB, the non-breeding season.

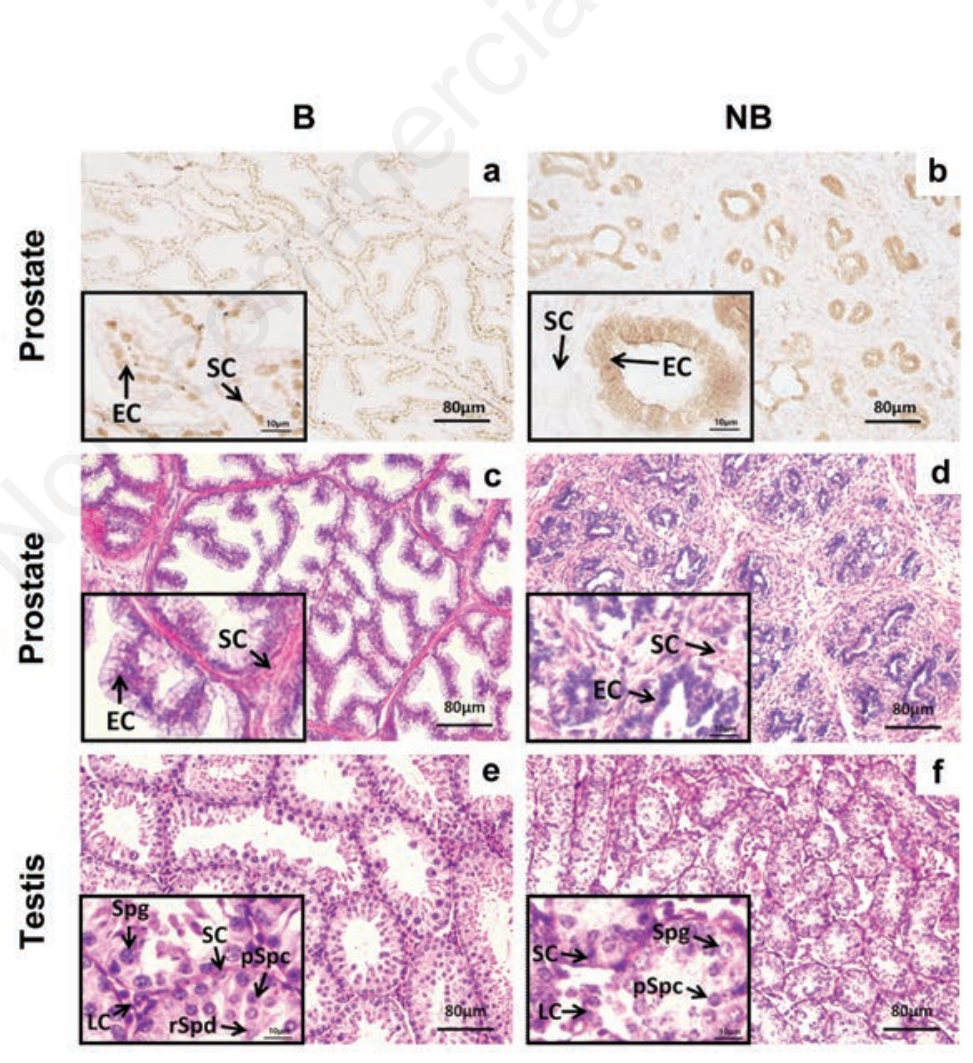

Figure 2. Histological features of the prostate of the wild ground squirrels in the breeding season and the non-breeding season. PSA serves as a validation of the prostate in the breeding (a) and non-breeding seasons (b). Histological observations of the prostate in the breeding (c) and non-breeding seasons (d). Histological observations of the testis in the breeding (e) and non-breeding seasons (f). B, the breeding season; NB, the non-breeding season; EC, epithelial cell; SC, stromal cells; LC, Leydig cell; SC, Sertoli cell; Spg, spermatogonium; pSpc, primary spermatocyte; rSpd, round spermatid. Scale bars: $80 \mu \mathrm{m}$ and $10 \mu \mathrm{m}$. 
B
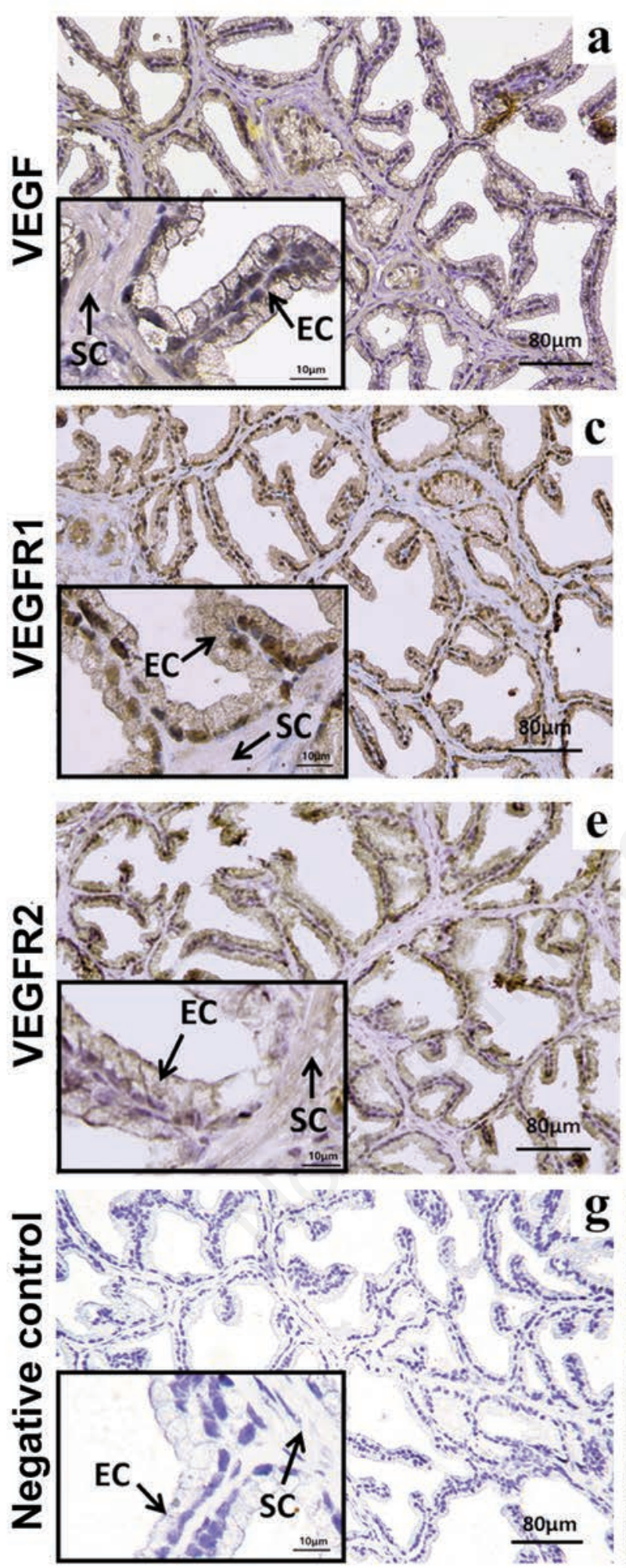

NB
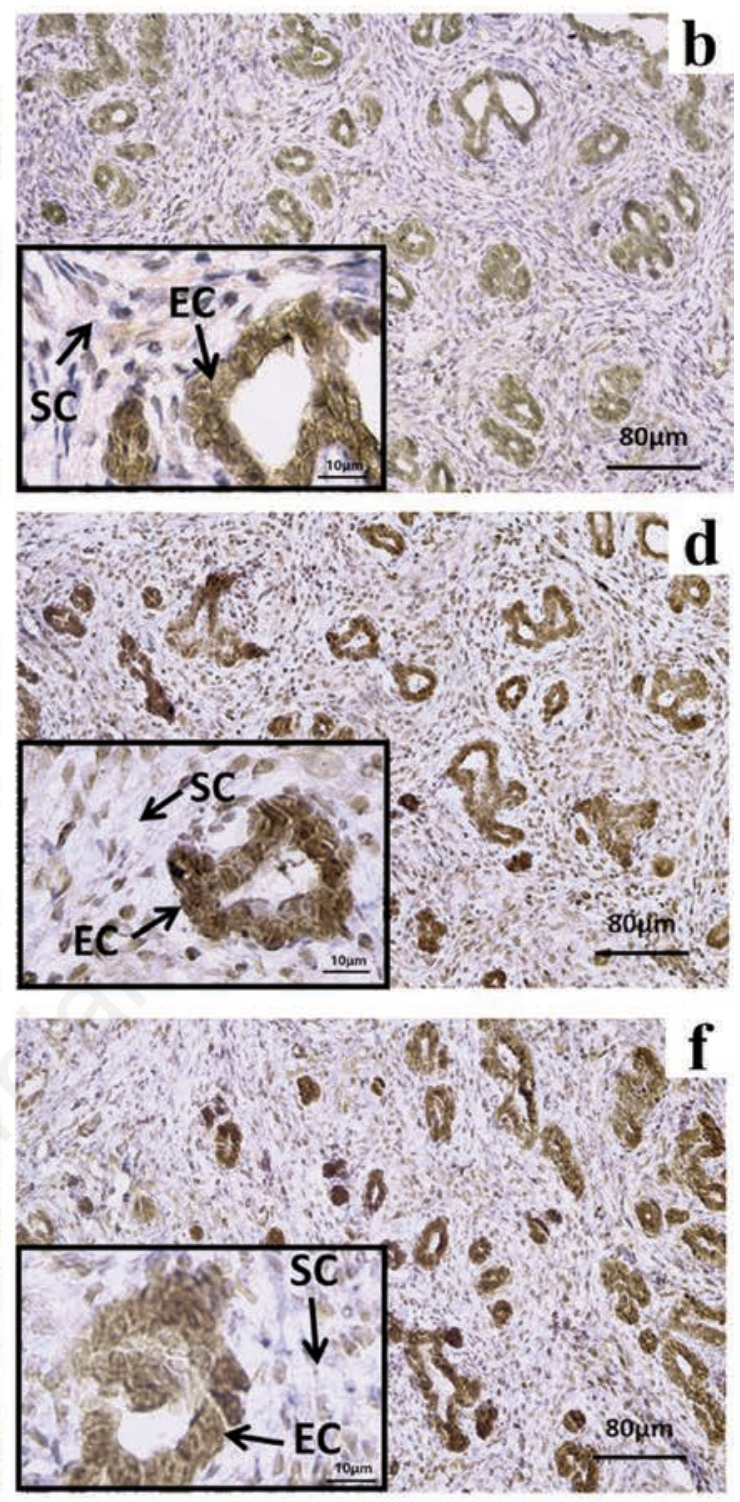

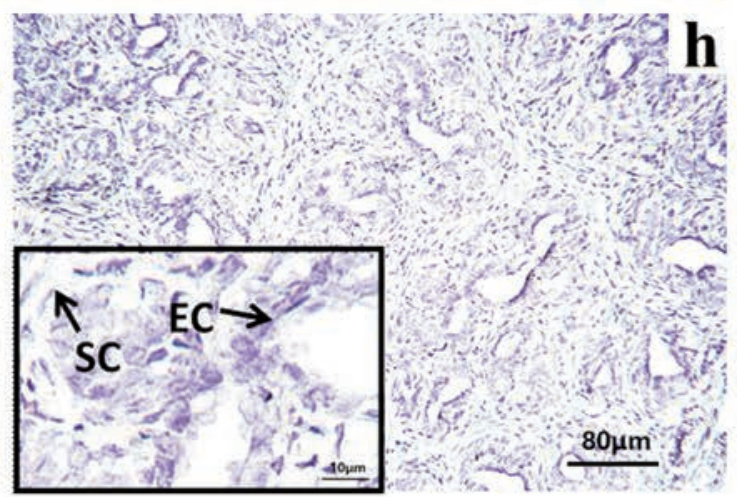

Figure 3. Immunolocalizations of VEGF, VEGFR1 and VEGFR2 in the prostate of the wild ground squirrels. Black arrows indicate the two cell types: epithelial cells and stromal cells. Immunolocalizations of VEGF in the prostate glands of wild ground squirrels during the breeding (a) and non-breeding seasons (b). Immunolocalizations of VEGFR1 in the prostate glands of wild ground squirrels during the breeding (c) and non-breeding seasons (d). Immunolocalizations of VEGFR2 in the prostate glands of wild ground squirrels during the breeding (e) and non-breeding seasons (f). Sections were treated with normal rabbit serum instead of primary antisera represent negative controls of the breeding (g) and non-breeding seasons (h). B, the breeding season; NB, the non-breeding season; EC, epithelial cell; SC, stromal cells. Scale bars: $80 \mu \mathrm{m}$ and $10 \mu \mathrm{m}$. 
The linear correlation and diagram of the microvascular density, the prostatic weight and the mRNA expressions of VEGF and VEGFRs

The immunohistochemical results of CD105 and the linear correlation of microvascular density, the weight and the relative expression of VEGF and VEGFRs in the prostate of the wild ground squirrels in the breeding and non-breeding seasons are shown in Figure 6. CD105 was mainly localized in the interstitial region of the prostate during the breeding (Figure 6a) and nonbreeding seasons (Figure 6b). The microvascular density in the prostate of the wild ground squirrels during the breeding season was significantly higher than that during the non-breeding season (Figure 6c). The scatter pattern of the microvascular density was positively correlated with the weight of prostate (Figure 6d). Scatter diagram of relative expressions of VEGF and VEGFR2 were positively correlated with the microvascular density of the prostate $(\mathrm{p}<0.01)$ (Figure $6 \mathrm{e}, \mathrm{g})$, while the relative expression level of VEGFR1 was not correlated with the microvascular density of the prostate of the wild ground squirrels (Figure 6f).

\section{Discussion}

In the present study, we demonstrated clearly the respective expressions and localizations of VEGF, VEGFR1 and VEGFR2 in the prostate of the wild ground squirrels during the breeding and non-breeding seasons. The immunohistochemical data revealed that VEGF, VEGFR1 and VEGFR2 were presented in epithelial and stromal cells during the breeding and non-breeding seasons. In addition, the mRNA expression levels of $V E G F$ and VEGFR2 in the prostate were both correlated with the changes in the prostate morphology and functions during the breeding and non-breeding seasons. These findings suggested that the prostate was able to synthesize VEGF, and this might play an important regulatory role in the seasonal changes of the prostate functions via an autocrine/paracrine pathway.

The male reproductive organ of seasonal breeders underwent significant morphological and physiological alterations, so as to adapt to the seasonal environment changes. ${ }^{29}$ The morphological and histological characteristics of the affiliated gonads showed annual reproductive cycle changes with reproductive hormones. ${ }^{27}$ In this study, it was shown that the values of the prostate weight and volume in the breeding season were higher than those in the non-breeding season, while the histological observations revealed
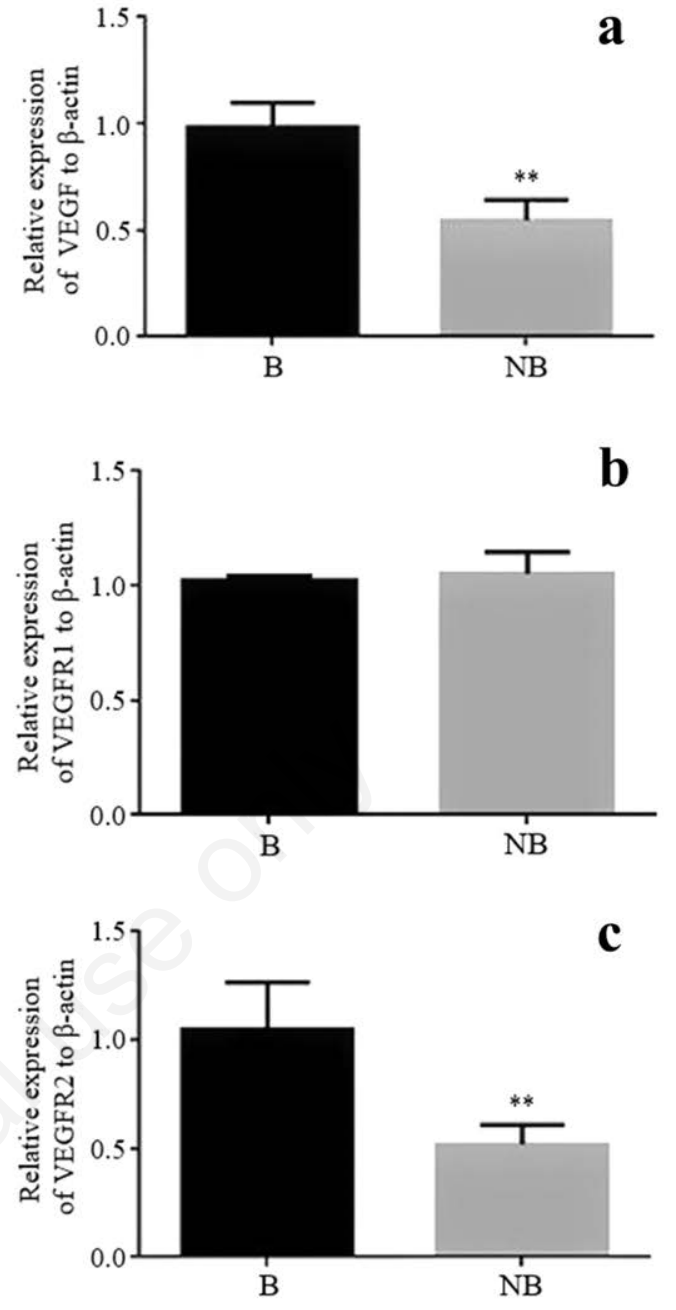

Figure 4. The mRNA expressions of VEGF, VEGFR1 and VEGFR2 detected by quantitative real-time PCR in the prostate of the wild ground squirrels during the breeding and non-breeding seasons. The relative mRNA levels of VEGF (a), VEGFR1 (b), and VEGFR2 (c) in the prostate of the wild ground squirrels during different seasons. The error bars represent the $\mathrm{SD}(\mathrm{n}=5$, each period). $\mathrm{B}$, the breeding season; $\mathrm{NB}$, the non-breeding season. ${ }^{*}$ Statistically significant values $\left({ }^{* *} \mathrm{p}<0.01\right)$. $\mathbf{a}$

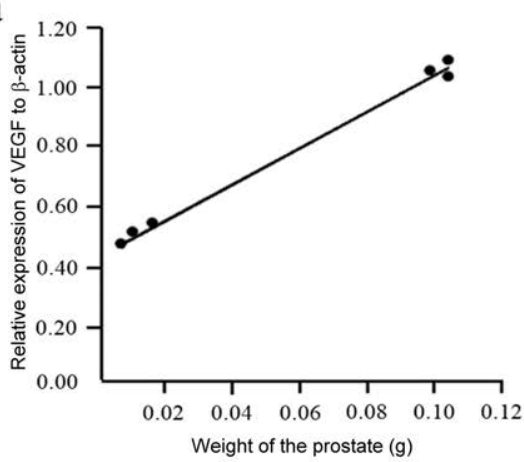

b

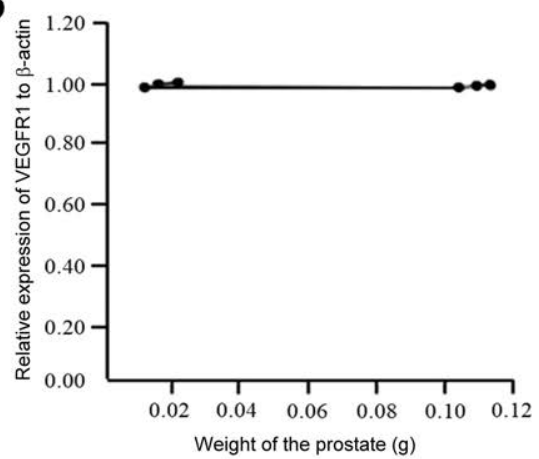

c

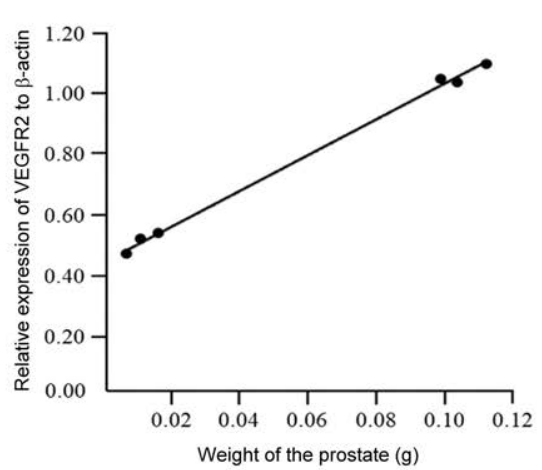

Figure 5. The linear correlation and scatter diagrams of relative expression of VEGF, VEGFR1 and VEGFR2 and weight of the prostate of the wild ground squirrels. Each dot means the relative mRNA level and weight of the prostate of three individual the wild ground squirrels obtained in the breeding $(n=3)$ and non-breeding seasons $(n=3)$. a) $R=0.969, P<0.01$. b) $R=0.006, p=0.907$. c) $R=0.987, p<0.01$. 
B
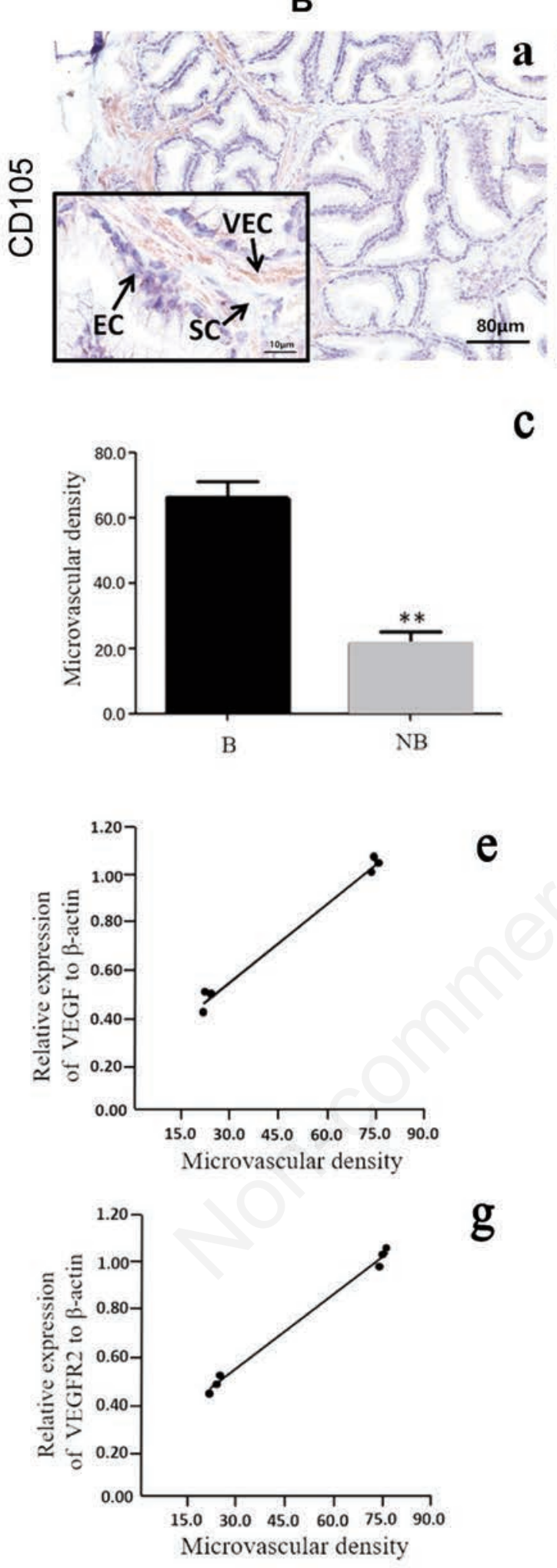

g
NB

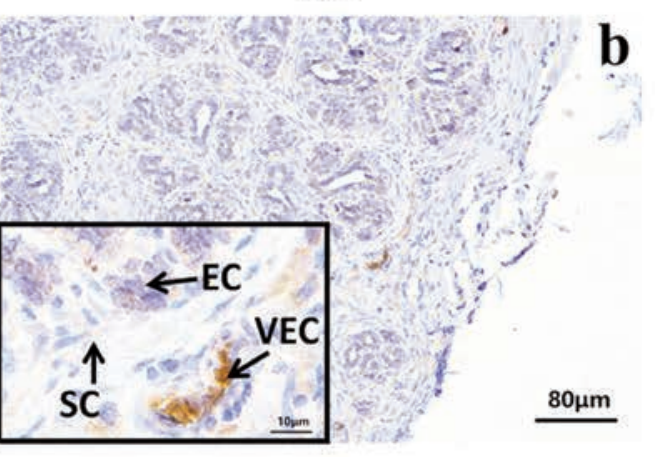

d
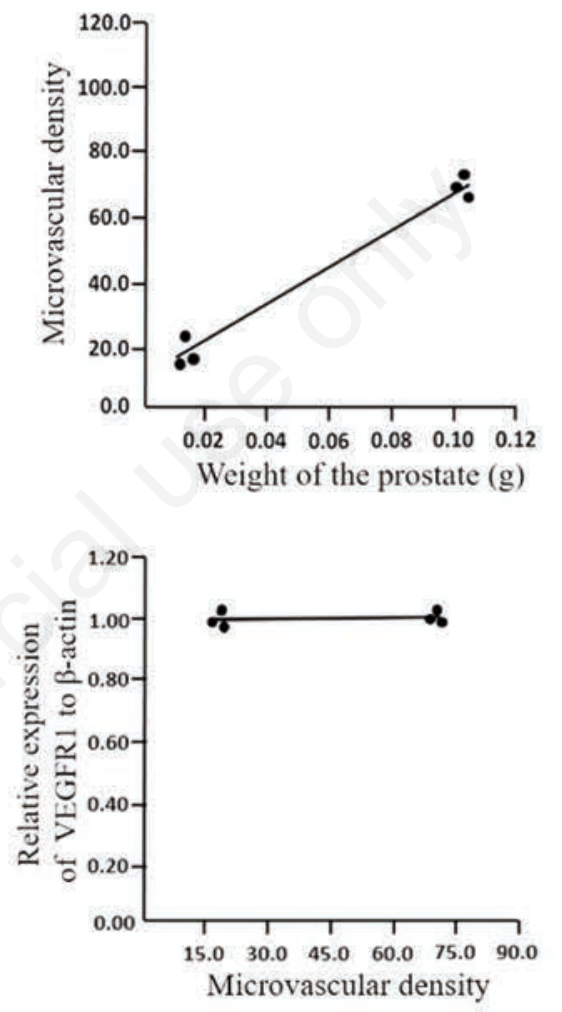

f

Figure 6. Immunolocalizations of CD105, the linear correlation of microvascular density, the weight and the relative expression of VEGF and VEGFRs in the prostate of the wild ground squirrels in the breeding and non-breeding seasons. Immunostaining of CD105 in the prostate of the wild ground squirrels during the breeding (a) and non-breeding seasons (b). The microvascular density in the prostate of the wild ground squirrels (c). The linear correlation and scatter diagrams of microvascular density and the prostate weight in the wild ground squirrels (d). The linear correlation and scatter diagrams of microvascular density and VEGF (e), VEGFR1 (f) as well as VEGFR2 (g) in the wild ground squirrels. The Each dot shows the microvascular density, relative mRNA level or weight of the prostate of wild ground squirrels obtained in the breeding $(n=3)$ and non-breeding seasons $(n=3)$. $B$, the breeding season; NB, the nonbreeding season. e) $R=0.958, p<0.01$. f) $R=0.007, p=0.912$. g) $R=0.974, p<0.01$. 
that the exocrine lumens in the prostate were expanded in the breeding season and contracted in the non-breeding season. This seasonal variation of the prostate shown in the present study was in agreement with previous reports regarding this species..$^{26,27}$ In addition, the present results showed that CD105 was strongly expressed in angiogenic vascular endothelial cells of the prostate during the breeding season than that in the non-breeding season, indicating that the microvessels of the prostate were widely distributed and the number of the microvessels increased obviously in the breeding season. This finding might be related to the increased nutrient supply and metabolism required for the rapid prostate development during the breeding season. Our previous studies indicated that significant seasonal changes occurred in the testes and epididymis of the wild ground squirrels in terms of both morphology and histology, which suggested that the male reproductive relative organs of the wild ground squirrels were highly developed during the breeding season. ${ }^{26,27}$ This conclusion was similar to that of other seasonal breeding mammals, including the raccoon dog, ${ }^{30}$ black bear ${ }^{31}$ and roe deer, ${ }^{32}$ which showed increased activity in the reproductive organs during their reproductive period. Therefore, the present results further supported the views that augmentation in reproductive organ size and function could be an optimal strategy formed throughout evolution for seasonal breeders. ${ }^{33}$

It was also shown that VEGF could regulate most of the endothelial response, such as the proliferation and migration of endothelial cells in the prostate, vascular permeability, and the selection of tip and stalk cells. ${ }^{13,34}$ VEGF signaling also regulated organ homeostasis in adults; e.g., when an organ was exposed to severe injury, VEGF induced the release of paracrine factors from endothelial cells, which in turn increased the rate of regeneration of the organ. ${ }^{35}$ In the present study, VEGF, VEGFR1 and VEGFR2 were presented in epithelial and stromal cells during both the breeding and non-breeding seasons, which suggested that the prostate of the wild male ground squirrels potentially possessed the ability to synthesize VEGF and its receptors, and it was concluded that VEGF might affect the physiological functions of the prostate. Similar results also were observed in other breeding mammals, including human, ${ }^{36}$ mice $^{37}$ and $\operatorname{dogs},{ }^{38}$ which showed that VEGF and its receptors regulated a series of physiological responses, such as proliferation and migration of prostatic endothelial cells and vascular permeability, in the form of paracrine or autocrine. Our previous studies showed that COX-1, COX-2, prostaglandin E synthase (PTGES) and prostaglandins E2 receptors (PTGERs) were expressed in the epithelial and stromal cells of the prostate during the breeding and non-breeding seasons, thus suggesting that PGE2 synthesis and signaling might play an important autocrine or paracrine role in the regulation of seasonal changes in the prostatic function of the wild ground squirrels. ${ }^{39}$ Other studies have also shown that androgens adjust most of the endothelial response by regulating a quantity of downstream growth factors, ${ }^{40}$ including VEGF ${ }^{41}$ and COX-2. ${ }^{39}$ The present study further addressed the view that local intrinsic factors might operate in concert with testicular steroid hormones, thereby playing an important regulatory role in the prostatic function of male mammals. ${ }^{42,43}$

VEGF, as a major signaling protein that activates and promotes mitosis and permeability of vascular endothelial cells, has been shown to serve an important function in regulating angiogenesis and vascular permeability through its binding to receptors, which was closely related to the rapid expansion of the prostate. ${ }^{11}$ It is also different in human prostate circulating VEGF levels in normal prostate tissue, benign prostatic hyperplasia and prostate cancer. The VEGF expression level was lowest in normal prostate tissue, higher in benign prostatic hyperplasia, and highest in prostate cancer, ${ }^{44}$ thereby suggesting that VEGF plays a key role in the process of the prostate proliferation and differentiation. In this study, the mRNA levels of VEGF and VEGFR2 expression were significantly higher in the breeding season than the non-breeding season. However, the VEGFR1 expression level was not different between the two seasons, suggesting that VEGF-VEGFR2 signaling plays a key role in the regulation of seasonal expansion and retraction of the prostate in wild ground squirrels. Difference in expression levels of the two VEGF receptors were also present in other mammals, such as in mice, where VEGF signaling through VEGFR2 was found to be a major angiogenic pathway. ${ }^{45}$ However, in human prostate tissue, all ligands and receptors other than VEGFR2 were extensively stained in human benign prostate tissue and prostate cancer tissue. ${ }^{37}$ In human prostatic epithelial cells in particular, VEGF and VEGFR1 expression was higher in tumor tissue than in benign tissue. ${ }^{36}$ Combined with the above results, the present data were shown to be in agreement with the view that VEGF relies on various receptors to play a biological role in different mammalian prostates.

In conclusion, the present results clearly demonstrated that VEGF and its receptors were expressed in the prostate of the wild ground squirrels, and suggested that VEGF and its receptors might serve as pivotal regulators affecting the morphology and functions of the prostate via an autocrine/paracrine pathway. This study provided a basis for a comprehensive understanding of the seasonal expansion and retraction of the prostate of the wild ground squirrels. Future studies will be performed to delineate the finer details underlying this process.

\section{Acknowledgements}

This research work was supported by National Natural Science Foundation of China (31872320, 21806010) and Natural Science Foundation of Beijing (8182039) and Young Scientist Start-up funding of Beijing Forestry University (BLX201714).

\section{References}

1. Powers GL, Marker PC. Recent advances in prostate development and links to prostatic diseases. Wiley Interdiscip Rev Syst Biol Med 2013;5:243-56.

2. Cook C, Vezina CM, Allgeier SH, Shaw A, Yu M, Peterson $\mathrm{RE}$, et al. Noggin is required for normal lobe patterning and ductal budding in the mouse prostate. Dev Biol 2007;312:217-30.

3. Wang GC, Zhao D, Spring DJ, DePinho RA. Genetics and biology of prostate cancer. Genes Dev 2018;32:1105-40.

4. Omabe M, Ezeani M. Infection, inflammation and prostate carcinogenesis. Infect Genet Evol 2011;11:1195-8.

5. Singh M, Jha R, Melamed J, Shapiro E, Hayward SW, Lee P. Stromal androgen receptor in prostate development and cancer. Am J Pathol 2014;184:2598-607.

6. Hoover P, Naz RK. Do men with prostate abnormalities (prostatitis/benign prostatic hyperplasia/prostate cancer) develop immunity to spermatozoa or seminal plasma? Int $\mathbf{J}$ Androl 2012;35:608-15.

7. Kumar VL, Majumder PK. Prostate: structure, functions and regulation. Int Urol Nephrol 1995;27:231-43.

8. Ceci C, Atzori MG, Lacal PM, Graziani G. Role of VEGFs/VEGFR-1 signaling and its inhibition in modulat- 
ing tumor invasion: Experimental evidence in different metastatic cancer models. Int J Mol Sci 2020;21:1388.

9. Langan RC. Benign prostatic hyperplasia. Prim Care. 2019;46:223-32.

10. Fantone S, Tossetta G, Montironi R, Senzacqua M, Marzioni D, Mazzucchelli R. Ciliary neurotrophic factor (CNTF) and its receptor (CNTFR $\alpha$ ) signal through MAPK/ERK pathway in human prostate tissues: a morphological and biomolecular study. Eur J Histochem 2020;64:3147.

11. Apte RS, Chen DS, Ferrara N. VEGF in signaling and disease: Beyond discovery and development. Cell 2019;176:1248-64.

12. Melincovici CS, Boşca AB, Şuşman S, Mărginean M, Mihu $\mathrm{C}$, Istrate $\mathrm{M}$, et al. Vascular endothelial growth factor (VEGF) - key factor in normal and pathological angiogenesis. Rom J Morphol Embryol 2018;59:455-67.

13. Zhang QY, Qiu SD, Ge L. Studies on expression and location of VEGF protein in rat testis and epididymis. Shi Yan Sheng Wu Xue Bao 2004;37:1-8.

14. Grivas N, Goussia A, Stefanou D, Giannakis D. Microvascular density and immunohistochemical expression of VEGF, VEGFR-1 and VEGFR-2 in benign prostatic hyperplasia, high-grade prostate intraepithelial neoplasia and prostate cancer. Cent European J Urol 2016;69:63-71.

15. Movsas TZ, Sigler R, Muthusamy A. Vitreous levels of luteinizing hormone and VEGF are strongly correlated in healthy mammalian eyes. Curr Eye Res 2018;43:1041-4.

16. Movsas TZ, Sigler R, Muthusamy A. Elimination of signaling by the luteinizing hormone receptor reduces ocular VEGF and retinal vascularization during mouse eye development. Curr Eye Res 2018;43:1286-9.

17. Kazi AA, Molitoris KH, Koos RD. Estrogen rapidly activates the PI3K/AKT pathway and hypoxia-inducible factor 1 and induces vascular endothelial growth factor A expression in luminal epithelial cells of the rat uterus. Biol Reprod 2009;81:378-87.

18. Yang M, Wang L, Wang X, Wang XZ, Yang ZQ, Li JX. IL6 promotes FSH-induced VEGF expression through JAK/STAT3 signaling pathway in bovine granulosa cells. Cell Physiol Biochem 2017;44:293-302.

19. Rudolfsson SH, Wikström P, Jonsson A, Collin O, Bergh A. Hormonal regulation and functional role of vascular endothelial growth factor a in the rat testis. Biol Reprod 2004; $70: 340-7$.

20. Hwang GS, Wang SW, Tseng WM, Yu CH, Wang PS. Effect of hypoxia on the release of vascular endothelial growth factor and testosterone in mouse TM3 Leydig cells. Am J Physiol Endocrinol Metab 2007;292:E1763-E1769.

21. Eisermann K, Fraizer G. The androgen receptor and VEGF: Mechanisms of androgen-regulated angiogenesis in prostate cancer. Cancers (Basel) 2017;9:32.

22. Ma T, Yang SL, Jing HY, Cong L, Cao ZX, Liu ZL, et al. Apparent diffusion coefficients in prostate cancer: correlation with molecular markers Ki-67, HIF-1 $\alpha$ and VEGF. NMR Biomed 2018;31:nbm.3884.

23. Wang Y, Wang ZY, Yu WY, Sheng X, Zhang HL, Han YY, et al. Seasonal expressions of androgen receptor, estrogen receptors and cytochrome $\mathrm{P} 450$ aromatase in the uteri of the wild Daurian ground squirrels (Spermophilus dauricus). Eur J Histochem 2018;62:2889.

24. Han YY, Zhan JQ, Xu Y, Zhang FW, Yuan ZR, Weng Q. Proliferation and apoptosis processes in the seasonal testicular development of the wild Daurian ground squirrel (Citellus dauricus Brandt, 1844). Reprod Fertil Dev
2017;29:1680-8.

25. Li QL, Zhang FW, Zhang S, Sheng X, Han YY, Weng Q, et al. Seasonal expression of androgen receptor, aromatase, and estrogen receptor alpha and beta in the testis of the wild ground squirrel (Citellus dauricus Brandt). Eur J Histochem. 2015;59(1):2456.

26. Wang Y, Yao YC, Zhang CJ, Guo YY, Zhang HL, Han YY, et al. Seasonal expressions of COX-1, COX-2 and EP4 in the uteri of the wild Daurian ground squirrels (Spermophilus dauricus). Prostains Other Lipid Mediat 2019;143:106343.

27. Zhang Y, Wang Y, Huang C, Wang Y, Qi HY, Han YY, et al. Seasonal expression of $5 \alpha$-reductases and androgen receptor in the prostate of the wild ground squirrel (Spermophilus dauricus). Comp Biochem Physiol A Mol Integr Physiol 2018;226:11-6.

28. Weng JJ, Li B, Sheng X, Zhang HL, Hu X, Zhou J, et al. Seasonal changes in immunoreactivity of vascular endothelial factor and its receptors VEGFR1 and VEGFR2 in the uterus of wild ground squirrels (Citellus dauricus Brandt). J Reprod Dev 2012;58:537-43.

29. Jiménez R, Burgos M, Barrionuevo FJ. Circannual testis changes in seasonally breeding mammals. Sex Dev 2015;9:205-25.

30. Qiang W, Murase T, Tsubota T. Seasonal changes in spermatogenesis and testicular steroidogenesis in wild male raccoon dogs (Nyctereutes procynoides). J Vet Med Sci 2003;65:1087-92.

31. Tsubota T, Howell-Skalla L, Nitta H, Osawa Y, Mason JI, Meiers PG, et al. Seasonal changes in spermatogenesis and testicular steroidogenesis in the male black bear Ursus americanus. J Reprod Fertil 1997;109:21-7.

32. Klonisch T, Schön J, Hombach-Klonisch S, Blottner S. The roe deer as a model for studying seasonal regulation of testis function. Int J Androl 2006;29:122-8.

33. Williams CT, Klaassen M, Barnes BM, Buck CL, Arnold W, Giroud S, et al. Seasonal reproductive tactics: annual timing and the capital-to-income breeder continuum. Philos Trans R Soc Lond B Biol Sci 2017;372:20160250.

34. Breier G, Damert A, Plate KH, Risau W. Angiogenesis in embryos and ischemic diseases. Thromb Haemost 1997;78:678-83.

35. Pandya NM, Dhalla NS, Santani DD. Angiogenesis--a new target for future therapy. Vascul Pharmacol 2006;44:265-74.

36. Ferrer FA, Miller LJ, Andrawis RI, Kurtzman SH, Albertsen PC, Laudone VP, et al. Vascular endothelial growth factor (VEGF) expression in human prostate cancer: in situ and in vitro expression of VEGF by human prostate cancer cells. J Urol 1997;157:2329-33.

37. Woollard DJ, Opeskin K, Coso S, Wu D, Baldwin ME, Williams ED. Differential expression of VEGF ligands and receptors in prostate cancer. Prostate 2013;73:563-72.

38. Palmieri C. Immunohistochemical expression of angiogenic factors by neoplastic epithelial cells is associated with canine prostatic carcinogenesis. Vet Pathol 2015;52:607-13.

39. Chen Z, Yao YC, Shen YY, Zhang A, Zhang Y, Xie W, et al. Seasonal expressions of prostaglandin $\mathrm{E}$ synthases and receptors in the prostate of the wild ground squirrel (Spermophilus dauricus). Prostaglandins Other Lipid Mediat 2020;148:106412.

40. Sampson N, Madersbacher S, Berger P. [Pathophysiologie und Therapie der benignen ProstataHyperplasie(Pathophysiology and therapy of benign prostatic hyperplasia)].[Article in German]. Wien Klin Wochenschr 2008;120:390-401. 
41. Lissbrant IF, Hammarsten P, Lissbrant E, Ferrara N, Rudolfsson SH, Bergh A. Neutralizing VEGF bioactivity with a soluble chimeric VEGF-receptor protein flt(1-3)IgG inhibits testosterone-stimulated prostate growth in castrated mice. Prostate 2004;58:57-65.

42. Sinowatz F, Amselgruber W, Plendl J, Kölle S, Neumüller C, Boos G. Effects of hormones on the prostate in adult and aging men and animals. Microsc Res Tech 1995;30:282-92.

43. Joseph IB, Nelson JB, Denmeade SR, Isaacs JT. Androgens regulate vascular endothelial growth factor content in nor- mal and malignant prostatic tissue. Clin Cancer Res 1997;3:2507-11.

44. Wang L, Chen ZJ, Wang QT, Cao WF, Jian Y, Wang SX, et al. Expression of hypoxia-inducible factor 1 alpha and vascular endothelial growth factor in prostate cancer and its significance. Zhonghua Nan Ke Xue 2006;12:57-9.

45. Lohela M, Bry M, Tammela T, Alitalo K. VEGFs and receptors involved in angiogenesis versus lymphangiogenesis. Curr Opin Cell Biol 2009;21:154-65.

Received for publication: 12 January 2021. Accepted for publication: 3 March 2021.

This work is licensed under a Creative Commons Attribution-NonCommercial 4.0 International License (CC BY-NC 4.0).

CCopyright: the Author(s), 2021

Licensee PAGEPress, Italy

European Journal of Histochemistry 2021; 65:3219

doi:10.4081/ejh.2021.3219 